\title{
Chaos as Emergence: Comparative Study of William S. Burroughs' Naked Lunch and Charu Niveditha's Zero Degree
}

\author{
Dr. Meadows B. \\ (Department of English \& Foreign Languages, SRM University, India)
}

\begin{abstract}
Conforming to the American school of comparative literature, an attempt is made to compare two semiautobiographical cum fictional works from different geographical areas - the United States and Indiawith exclusive focus on the modus operandi employed to narrate the books. The books Naked Lunch (1959) by William S. Burroughs and Zero Degree (1998) by Charu Niveditha (Translated into English from Tamil by Pritham K Chakravarthy \& Rakesh Khanna, 2008) were written half a century apart, in an entirely contrasting literary as well as social background, yet a striking similarity unites these books in a rather astonishing manner - the nonlinearity in the narration of the social issues in a chaotic and explicit manner. These books share similarity not just in structure, narration, and content but also in the reception of the books among masses. This paper attempts to delineate those unifying qualities and also highlight the subtle cultural differences they exhibit.
\end{abstract}

Keywords: Burroughs, comparative, nonlinear narrative, transgressive

Every work of art is unique but it is inevitable to compare and contrast it with others. Inadvertently, a similarity or shade of a previous or another work is reflected in it; sometimes it is simply a copy of the original or an adaptation. It is only natural for an artist to be impressed by a piece of music, a sculpture, or a book and in some way reproduce it in their own product. All instances are not intentional and hence it can be said that there had been an influence of the original. While this is true in most cases, some look-alike works are simply accidental and not intentional. It is an interesting branch of study to understand two works of art and compare them by analyzing their uniqueness or unifying factors. Comparative literature is a drop-in-the-ocean attempt to understand literary works in a wider background in relation to or in comparison to other works. In simpler terms, comparative literature, or shortly comp. litt., is basically a study not only of the relationship between literature of two or more linguistic, cultural, and national group but also other areas of knowledge and belief such as painting, culture, music, philosophy and social sciences.

The two major literary schools with standard perspectives on comparative study are the French and the American School. The French school endeavours to trace the origin of a work, in that, how it influences other works or was influenced by other works. The American school limits itself to critical analysis of literary aspects in works from not just a particular region, but from different areas, with little or no emphasis on the influences. Like any field, comparative literature also has come a long way in its definition and application and is no longer confined to its traditional limitations.

In line with the American school, attempt is made to compare two texts from two entirely different countries, and culture more specifically, and analyse their unifying factors. William S. Burroughs' Naked Lunch (1959) and Charu Niveditha's Zero Degree (1998) are literary works once disputed as to their credibility as literary pieces. These books are classified more as pulp fiction for their explicit content. They are known specifically for their non-linear narrative and transgressive content. Naked Lunch is an American book, written in English, around mid $20^{\text {th }}$ century, but much ahead of its time in content and technicality. It had created a great furor in the literary scene then. Zero Degree is an Indian book, written in Tamil by Charu Niveditha, which came as a cultural shock to a rather conservative Indian mind, and both the author and the work became objects of contempt and disdain. It was further translated into Malayalam a year later by Balasubramaniam and P.M. Girish and into English in 2008 by Pritham K. Chakravarthy and Rakesh Khanna. This paper is an attempt to compare and delineate the similarity of these books in structure, narration, content and even the reception of the books among masses. The main contrast between these books is the cultural polarity of their authors.

What lends uniqueness to these texts is their narrative. There is absence of a coherent, linear story. In a structured text, the narration is linear, that is in the chronological order or in the sequence of the happenings. Nonlinearity is what adorns both Naked Lunch and Zero Degree and lends them an ethereal feel. The nonlinearity here is not the traditional flashback technique as in Faulkner or Woolf, but a total revamping of conventional narrative form and experimentation beyond imagination and fancy. What conservatists would call chaos, Burroughs and Niveditha might call an emergence of a new trend in the art of storytelling. Both the texts 
contain not just a story which is devoid of linearity but that which is also a mixture or assortment of different types of texts.

Naked Lunch is a compilation of notes written over a long time by the author and connected loosely and illogically with not just his own notes but also with writings of other authors.

“... He [Burroughs] started inserting shards of sentences and paragraphs from newspapers and other authors into his own prose because, he said, he wanted to break the patterns that one normally finds in a book and emulate the peripheral impressions experienced in life itself." (CLC 182) [1]

The voice is multifaceted; it varies, character to character. Naked Lunch is devoid of any pattern in the text and contents overlap beyond understanding. While Naked Lunch is chaos in prose, Zero Degree is a bouquet of stories, telephonic conversations, poems, etc., juxtaposed without any continuity or coherence. Here again the voice is of a narrator not necessarily belonging to a single story. To the author's own confession in the book, it is a "bunch of notes" put together.

Both Naked Lunch and Zero Degree are more of a collection of the authors' notes than any intentional story telling as such. The authors make it obvious and admit to possessing the desire to not write a linear story. Burroughs in an interview said, "I don't plan a book out. I don't know how it's going to end." Niveditha mentions in the beginning of his novel, "The chapters have become shuffled. I might have had some ulterior motive." Both texts are not an easy read and require more than one complete reading to get in sync with the author's intention of the book. An interesting point is that these books can be read from any point and still give the same reading effect.

The books have been under public and legal scanner for obscenity and explicit content. It cannot be denied that these texts contain depiction of hard core sexuality - both homo and hetero and also some violent sadomasochistic acts. But that is not all; there is more to the book than this nakedness - an underlying powerful incident or theme fueling the content of the book. When the narrative technique of a text is under so much discussion, the question arises as to its content or the story line. Contrary to what most people think about Naked Lunch and Zero Degree, both the texts do not contain underlying message but a rather straightforward and forthright observation of certain irrepressible and inexpressible social issues. Sex is a common theme in both the books and the texts are unique for laying bare in detail the issues of drug addiction and women's psyche in Naked Lunch and Zero Degree respectively.

The horrific moments of withdrawal experienced while on cure for drug addiction makes for the most of the text of Naked Lunch. "Naked Lunch purports to be a record of a man's addiction to opiates, his apomorphine treatment, and cure. On the literal level, the novel can be seen as the disjointed memories and hallucinations of withdrawal" (Skerl 36) [2]. Interspersed with this are social themes like homosexuality, drug addiction, and governmental tyranny. Sexual contents include homosexual acts, sadomasochistic exploits and various other detestable references to bodily discharges. Plainly put, Naked Lunch is "composed of loosely related section containing graphic descriptions of drug use, murder, and sadomasochistic homosexual acts." (CLC 179)

Zero Degree traces the difficult ordeal of the Indian women caught between familial and financial responsibilities, at the same time facing physical, mental, and sexual harassment from all quarters including immediate family. The sexual perverseness which was kept hush-hush for quite a long time is boldly referred to in the book through various women characters. Juxtaposed with these sad tales are contents of two extremes titillating phone sex conversations and references to sadistic sexual pleasure on the one end; touching epistles from a father to daughter and poems by different characters on the other. Discussion of sexual issues, especially from a feminine perspective, was a bold move on part of Niveditha. In a nutshell, Zero Degree,

... takes the reader on a wildly curving, frequently detouring story made of phone sex, torture, love poetry, numerology, mythology, and what appears to be a decidedly Latin American thoughtscape, and interestingly, in this journey, the reader is both guided traveler and adventurer.

$$
\text { (http://archive.tehelka.com/story main41.asp?filename=hub201208style as.asp) [3] }
$$

Added to the fact that it is difficult to quantify these texts into a particular genre, these books also exhibit traits of science fiction elements. The plot of Naked Lunch is set in an imaginary region called Interzone. Skerl describes in detail thus:

Interzone is also described as a single building consisting of bedrooms and a polyglot Market ... inhabitants spend their time copulating, shooting up, and making deals in a parody of Western capitalistconsumer societies. (37)

Zero Degree while moving back and forth in time and character, includes characters like NinthCentury-A.D.-Dead-Brain which add charm akin to sci-fi books.

The nonlinearity and complexity of the texts are further complicated by abandoning grammatical and structural patterns of the sentences. Both Burroughs and Niveditha have taken pains to make their books one of a kind in the literary scene and have succeeded in evoking a response, even if not all that positive. Naked 
Lunch is already a cocktail of different type of contents and is further shaken up through typography. Skerl comments on this as follows:

The representation of the spoken word in print is responsible for Burroughs's unusual use of typography: his abundant capitals, italics, and ellipses ... The unusual typography emphasizes the unconventionality of the novel, its fragmentary nature, and the colloquial rather than literary style. (45 \& 46)

Zero Degree is one of the few non-linear novels in Tamil and one of the few lipogrammative novels in the world - which is an effort to consciously avoid use of certain words in the text throughout. The original Tamil text had been written without using the Tamil word for 'one'. While the content may be simply in a puttogether form, the style of the content is done painstakingly to stand out in a crowd. This can be best explained thus:

"Punctuation marks, grammar and sentence construction are given the miss, to deliberately create chaotic chapters. The narrative is interrupted by news reports, critiques on Latin American novelists and reports about Africa without any manners." (http://krazykochi.blogspot.in/2010/04/reading-zero-degree.html) [4]

This unconventional style of writing adopted by Burroughs and Niveditha shows how much effort has gone into creating these novels. Abandoning a convention is what requires courage and not following it. On a humourous note, it can be said that the authors have been too studious to make sure they follow nothing straight and traditional and yet attract attention - good and bad.

While both Naked Lunch and Zero Degree are standalone reads, the characters are seen to be overlapping from the authors' previous works. Naked Lunch begins with the drug quest of the protagonist William Lee, which was how Burroughs' previous book Junkie ended. Zero Degree contains a part of the novel written by one Misra who had committed suicide in Niveditha's Existentialism and Fancy Banyan. The author claims that this section was written before he committed suicide and is included in Zero Degree. It can be opined that Naked Lunch and Zero Degree are not the careless compilation of notes as always supposed, but do exhibit characteristics of continuity and coherence.

While much can be said about the unifying aspects of the novels Naked Lunch and Zero Degree, it has to be noted that these books belong to two extreme cultures. If Naked Lunch could evoke shock and disgust to a modern Western culture, what Zero Degree can do to a traditional nation like India, specifically the much conservative Tamil literati, need not be vocalized. The book brings unrest in the readers' mind. Dual thoughts evolve as to agree with the text or disagree with it. It is interesting to note that even the impact on the readers' psyche had been similar as follows:

“... Naked Lunch is a roller coaster ride through the psyche of a drug addict and a deviant world of junkies, perverts and hucksters." (CLC 185).

"Reading [Zero Degree] has been a roller coaster ride[;] often trash, often curious, often mediocre and brilliant at many places." (http://kpjayan.blogspot.in/2011/08/zero-degrees-charu-nivedita.html) [5]

As mentioned, the books indeed are a roller coaster ride, at times tempting to go through the euphoria again and other times repulsive due to the dizziness. Though the books have gone through grueling tests of sorts, they have withstood many onslaughts and emerged as fine literary masterpieces in their own way.

\section{References}

[1] CLC, "William S. Burroughs Dies at 83; Member of the Beat Generation Wrote Naked Lunch,", in The New York Times, August 3 , 1997, p. B5

[2] Skerl, Jennie. William S. Burroughs (Boston: Twayne Publishers, 1985)

[3] http://archive.tehelka.com/story_main41.asp?filename=hub201208style_as.asp

[4] http://krazykochi.blogspot.in/2010/04/reading-zero-degree.html

[5] http://kpjayan.blogspot.in/2011/08/zero-degrees-charu-nivedita.html 